\title{
Dextrin-Based Nanomagnetogel: In Vivo Biodistribution and Stability
}

\author{
C. Gonçalves, ${ }^{\dagger}$ J. P. Silva, ${ }^{\dagger}$ I. F. Antunes, ${ }^{\dagger}$ M. F. M. Ferreira, ${ }^{\#}$ J. A. Martins, ${ }^{\#}$ C. F. G. C. Geraldes, ${ }^{\perp}$ \\ Y. Lalatonne, ${ }^{\S}$ L. Motte, ${ }^{\S}$ E. F. J. de Vries, ${ }^{\ddagger}$ and F. M. Gama ${ }^{* \dagger}$ \\ ${ }^{\dagger}$ Centre of Biological Engineering and ${ }^{\#}$ Chemistry Department, University of Minho, 4710-057 Braga, Portugal \\ ${ }^{\ddagger}$ Department of Nuclear Medicine and Molecular Imaging, University of Groningen, University Medical Centre of Groningen, \\ Hanzeplein 1, 9713 GZ Groningen, The Netherlands \\ ${ }^{\perp}$ Chemistry Department, Faculty of Science and Technology, and Coimbra Chemistry Center, University of Coimbra, 3001-401 \\ Coimbra, Portugal \\ ${ }^{\S}$ CSPBAT Laboratory, UMR 7244 CNRS, Université Paris 13, Sorbonne Paris Cité, 93017 Bobigny, France
}

Supporting Information

ABSTRACT: The biodistribution profile of a new dextrin nanomagnetogel, which consists of $\gamma-\mathrm{Fe}_{2} \mathrm{O}_{3}$ superparamagnetic nanoparticles loaded within a polymeric matrix of modified dextrin, was studied in mice. The nanomagnetogel bear a monomodal size distribution profile (average diameter 110 $\mathrm{nm})$ close to neutral surface charge and higher relaxivity $\left(r_{2}=\right.$ 215-248 $\mathrm{mM}^{-1} \mathrm{~s}^{-1}$ and $\left.r_{2} / r_{1}=13-11\right)$ than those of commercial formulations $\left(r_{2}=160-177 \mathrm{mM}^{-1} \mathrm{~s}^{-1}\right.$ and $r_{2} / r_{1}=$ 4-7). Also, the observed blood half-life-approximately $4 \mathrm{~h}-$ is superior to that of similar commercially available formulations, which remain for a few minutes in circulation.

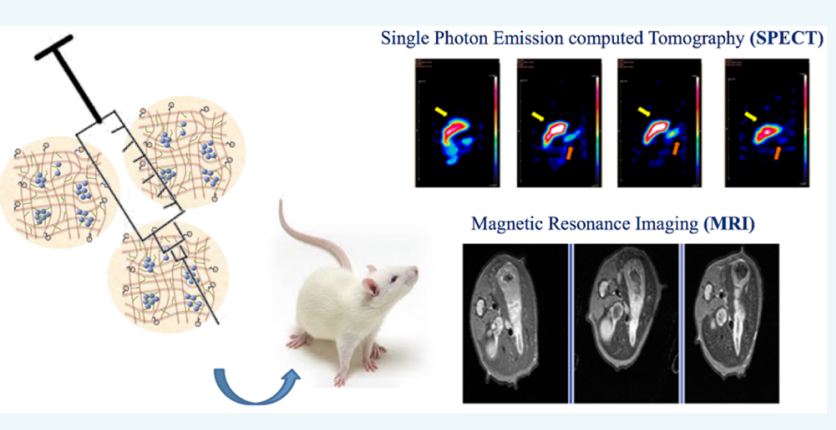
PEGylation resulted in 1.7- and 1.2-fold lower accumulation in the liver and spleen, respectively, within the first $24 \mathrm{~h}$. Noteworthy, a good correlation was obtained between the amount of polymer (quantified by scintigraphy) in the spleen, $48 \mathrm{~h}$ after administration, and the amount of iron physically loaded through hydrophobic interactions (quantified by ICP) indicating the absence of iron leakage from the polymeric matrix. This study provides evidence of the in vivo stability of a self-assembled nanomagnetogel, a relevant feature which is seldom reported in the literature.

\section{INTRODUCTION}

Bioprobes have enormous potential for clinical diagnosis due to enhanced detection and characterization of abnormal state of the body. Superparamagnetic iron oxide nanoparticles (SPION) have been extensively studied as magnetic resonance imaging (MRI) contrast agents. ${ }^{1}$ SPION need to be coated in order to allow formulation in aqueous solutions and to increase the stability in vitro and in vivo. ${ }^{2}$ The coating should be nontoxic and present high affinity for the iron oxide core. ${ }^{3}$ Clinically approved formulations consist on SPION coated with dextran or similar carbohydrates. ${ }^{4}$ After intravenous administration, SPION can be readily released if they are only weakly associated with the dextran coating, leading to aggregation and precipitation of the SPION under physiological conditions. ${ }^{5}$ Thus, stable incorporation of SPION within the nanocarrier is very important to ensure that they reach the target site. When the mononuclear phagocytic system is not the target, the opsonization and phagocytosis of nanoparticles should be avoided and the blood half-life should be long enough to allow accumulation on the target site. Grafting poly(ethylene glycol) (PEG) onto the surface of nanoparticles can decrease nanoparticle interactions with blood proteins, avoiding their recognition by the phagocytic system and thus increasing the circulation time. ${ }^{6}$
Magnetic properties, such as water proton relaxation rate enhancement $\left(R_{1,2}\right)$ and superparamagnetic behavior, are important features of SPION. These particles mainly produce $T_{2}$-relaxation effects, resulting in negative contrast in $T_{2^{-}}$ weighted images, which is determined by the translational diffusion of water molecules in the heterogeneous magnetic field surrounding the SPION. ${ }^{7}$ There are two major factors determining signal enhancement by SPION: the iron oxide core (size and density) and the coating (thickness and chemical composition). ${ }^{3}$ Increasing the size of bare SPION can increase its transverse relaxivity. ${ }^{8}$ However, large particles (diameter larger than approximately $15 \mathrm{~nm}$ ) easily aggregate in solution. ${ }^{9}$ A strategy to increase transverse relaxivity, while preserving the superparamagnetic properties, consists of clustering individual SPION within a polymeric structure. Previous studies indicate that clustering magnetic nanoparticles into polymeric micelles results in enhanced transverse relaxivity. ${ }^{10}$ Pharmacokinetics and organ/tissue distribution properties of nanocarriers are of great interest to predict their ability to reach the target site. A critical aspect of self-assembled nanosystems regards its stability after

Received: January 12, 2015

Revised: February 27, 2015

Published: March 3, 2015 
administration. Very little information is available in the literature on this topic, which is addressed here, following up on previous work by our group describing the production and characterization of the dextrin nanomagnetogel. ${ }^{11}$ In vivo quantification of the biodistribution of SPION-based nanogels using MRI is often difficult to perform due to artifacts from air/tissue (lungs) and motion. Furthermore, using a $T 2 *$ mapping as a quantitative method can be time-consuming. However, having a dual modality probe, combining single-photon emission computerized tomography (SPECT) and MRI, quantification of the biodistribution can be obtained measuring gamma photons emitted by radionuclides using SPECT instrumentation. To label the nanomagnetogel with a radionuclide, a $\omega$-thiol functionalized DOTA-monoamide type metal chelator (DOTA $=1,4,7,10$ tetraazacyclododecanetetraacetic acid) was used for covalent functionalization (via Michael addition) of the dextrin, and labeling (complexation) with the ${ }^{111} \mathrm{In}^{3+}$ radioisotope. For the sake of clarity, the term "nanoparticles" will be used for $\gamma-\mathrm{Fe}_{2} \mathrm{O}_{3}$ nanoparticles, "nanogels" for the polymeric matrix of dextrin, and "nanomagnetogels" for nanogels loaded with $\gamma$ - $\mathrm{Fe}_{2} \mathrm{O}_{3}$ nanoparticles.

\section{RESULTS}

Nanomagnetogel Characterization. The size distribution of the nanomagnetogel with and without PEG 5000 was determined by dynamic light scattering, before and after DOTA coupling. As can be seen in Table 1, the decoration of

Table 1. Average Diameter ( $z$-avg) and Polydispersity Index (PdI) of Bare Nanogel or Nanomagnetogel (pegylated or not) before and after DOTA Coupling

\begin{tabular}{lcc}
\multicolumn{1}{c}{ material } & $z$-avg $(\mathrm{nm})$ & PdI \\
dex & $23.9 \pm 0.423$ & $0.388 \pm 0.007$ \\
DOTAdex & $25.3 \pm 0.140$ & $0.341 \pm 0.006$ \\
dexPEG & $32.4 \pm 0.760$ & $0.442 \pm 0.014$ \\
DOTAdexPEG & $37.1 \pm 0.534$ & $0.275 \pm 0.017$ \\
dex_SPION & $111.5 \pm 2.368$ & $0.197 \pm 0.007$ \\
dexPEG_SPION & $113.7 \pm 1.227$ & $0.197 \pm 0.010$ \\
DOTAdex_SPION & $111.7 \pm 1.952$ & $0.227 \pm 0.015$ \\
DOTAdexPEG_SPION & $110.5 \pm 0.777$ & $0.215 \pm 0.005$
\end{tabular}

the nanomagnetogel does not have a significant effect on its average diameter. The size distribution profile exhibits a single peak with a remarkably narrow polydispersity index (PdI).

A substantial reorganization takes place upon loading the nanogel with the iron nanoparticles. The presence of iron nanoparticles induces swelling of the hydrophobic nanodomains within the nanogel leading to a larger average size (around 110 $\mathrm{nm}$ ) and a monomodal size distribution profile was obtained. A schematic representation of the nanomagnetogel structure is presented in Scheme 1.

The concentration of stabilized $\gamma-\mathrm{Fe}_{2} \mathrm{O}_{3}$ within the dextrin polymer was $4.0 \mathrm{mM}$, irrespective of being pegylated or not, as determined by atomic absorption spectroscopy.

The zeta potential of bare dextrin nanogels was previously reported as $-4.02 \mathrm{mV}^{6}$ Loading of SPIONs does not significantly change this value $(-7.77 \mathrm{mV} ; \mathrm{pH} 7.4)$, while the grafted DOTA macrocycle is expected to display an overall negative charge at $\mathrm{pH}$ 7.4. In fact, nanomagnetogel functionalization with the DOTA-monoamide chelator leads to a shift of the zeta potential into the negative region $(-24.4 \mathrm{mV} ; \mathrm{pH} 7.4)$, thus confirming the success of the reaction. After complexation of the
Scheme 1. Schematics of the ${ }^{111}$ In-Labeled Nanomagnetogel (pegylated)

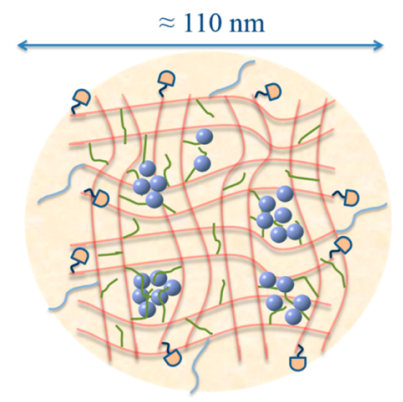

$$
\begin{aligned}
& \text { If Polymeric matrix (dextrin) } \\
& \text { Alkyl chains ( } 16 \text { carbons) } \\
& \gamma-\mathrm{Fe}_{2} \mathrm{O}_{3} \text { nanocrystals } \\
& { }^{111} \mathrm{In}^{3+} \text { complex } \\
& \text { PEG chains } 5,000
\end{aligned}
$$

DOTAdex SPION with cold (nonradioactive) $\mathrm{InCl}_{3}$, the zeta potential value returns to a near neutral value $(3.51 \mathrm{mV})$, consistent with the formation of neutral In(DOTA)dex_SPION complexes (Figure S1, Supporting Information).

The longitudinal $\left(r_{1}\right)$ and transverse $\left(r_{2}\right)$ relaxivities are good in vitro measures of the ability of the contrast agent to selectively reduce the relaxation times $T_{1}$ (spin-lattice relaxation time) and $T_{2}$ (spin-spin relaxation time) of the water protons, respectively, and thus of their efficiency as positive or negative MRI contrast agents. The inverse relaxation times, $R_{\mathrm{i}}\left(=1 / T_{\mathrm{i}}\right)$, vary linearly with the Fe concentration, according to eq 1

$$
R_{1,2}=r_{1,2}[\mathrm{Fe}]+R_{1,2}^{0}
$$

where $R_{1,2}^{0}$ are the inverse relaxation times of pure water. Relaxivities $r_{1}$ and $r_{2}$ were calculated through the least-squares curve fitting of $R_{1,2}=1 / T_{1,2}\left(\mathrm{~s}^{-1}\right)$ versus the iron concentration ( $\mathrm{mM} \mathrm{Fe}$ ) according to eq 1 (Figure $\mathrm{S} 2$, Supporting Information).

Table 2 shows the calculated $r_{1}$ and $r_{2}$ relaxivities of the dex_SPION and dexPEG_SPION prepared in this work. Both

Table 2. Longitudinal $\left(r_{1}\right)$ and Transverse $\left(r_{2}\right)$ Relaxivities $\left(25^{\circ} \mathrm{C}, 0.47 \mathrm{~T}, 20 \mathrm{MHz}\right)$ of dex SPION and dexPEG SPION Compared with Commercial Products

\begin{tabular}{llll} 
& \multicolumn{1}{c}{$r_{1} / \mathrm{mM}^{-1}$} & $r_{2} / \mathrm{mM}^{-1}$ & $r_{2} /$ \\
$\mathrm{s}^{-1}$ & $\mathrm{~s}_{1}$ & $r_{1}$ \\
material & $17 \pm 0.2$ & $215 \pm 3.6$ & 13 \\
dex_SPION & $23 \pm 0.1$ & $248 \pm 4.9$ & 11 \\
dexPEG_SPION $_{\text {Ferumoxides (AMI-25, Feridex, }}$ & 40 & 160 & 4 \\
$\begin{array}{l}\text { Endorem) } \\
\text { Ferucarbotran (Resovist) }\end{array}$ & 25 & 177 & 7 \\
\hline
\end{tabular}

formulations display higher $r_{2}$, but lower $r_{1}$ than similar commercial formulations (ferumoxides and ferucarbotran).

Superparamagnetic behavior of the formulations was confirmed with a MIAplex magnetometer at room temperature. The second derivative of the magnetization curves obtained for the pegylated nanomagnetogel is not modified compared to the unpegylated formulation. The absence of hysteresis loops indicates that the formulations preserve their superparamagnetic behavior (Figure S3, Supporting Information). ${ }^{14}$

Blood Clearance and Biodistribution. To evaluate the fate of the ${ }^{111}$ In-labeled nanogels and nanomagnetogels in vivo, ex vivo biodistribution studies were performed in wild-type mice, focusing on blood clearance and accumulation in the main excretory organs (liver, spleen, kidneys).

Among the ${ }^{111}$ In-labeled formulations studied, the smaller unloaded $\left[{ }^{111}\right.$ In]DOTAdex nanogel showed significantly higher blood levels $1 \mathrm{~h}$ after injection, as compared to the larger SPION 
loaded nanomagnetogels (Figure 1). For longer periods few differences are observed among the formulations regarding blood

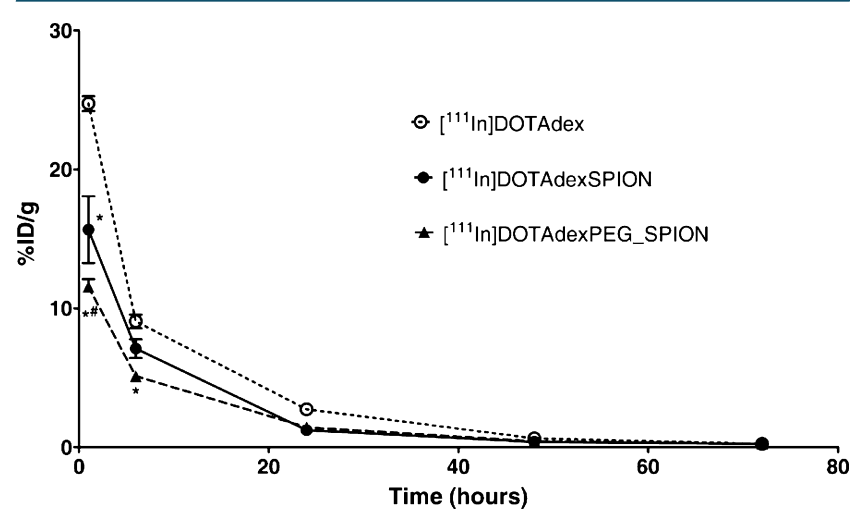

Figure 1. Retention of $\left[{ }^{111} \mathrm{In}\right]$ DOTAdex, $\left[{ }^{111} \mathrm{In}\right] \mathrm{DOTAdexSPION}$, or $\left[{ }^{111}\right.$ In]DOTAdexPEG_SPION over $72 \mathrm{~h}$ in mice plasma. Bars represent mean \pm standard error of the mean of the \% ID $/ \mathrm{g}(n=5)$. * $p<0.001$ when compared to $\left[{ }^{111}\right.$ In]DOTAdex, ${ }^{\#} p<0.001$ when compared to $\left[{ }^{111} \mathrm{In}\right]$ DOTAdexSPION.

levels. Fitting the blood retention to a monoexponential decay model affords a blood half-life of approximately $4 \mathrm{~h}$ for all ${ }^{111} \mathrm{In}$ labeled formulations.

The uptake of ${ }^{111}$ In-labeled nanogels or nanomagnetogels in different organs was evaluated and expressed as the fraction of injected dose per gram of tissue (\%ID/g). Figure 2 shows that the unloaded $\left[{ }^{111} \mathrm{In}\right]$ DOTAdex generally presented significantly lower uptake in the liver, spleen, and kidneys than the loaded counterpart. A significant lower uptake was observed for the pegylated nanomagnetogels, in the spleen, up to $72 \mathrm{~h}$ after administration, when compared with unpegylated formulations. In the liver, the uptake is inferior for pegylated nanomagnetogels, but only in the initial $24 \mathrm{~h}$, reaching after this period of time similar values of unpegylated formulations.

In Vivo SPECT and MRI Imaging. Figure 3 shows the sagittal SPECT images of mice injected with the different
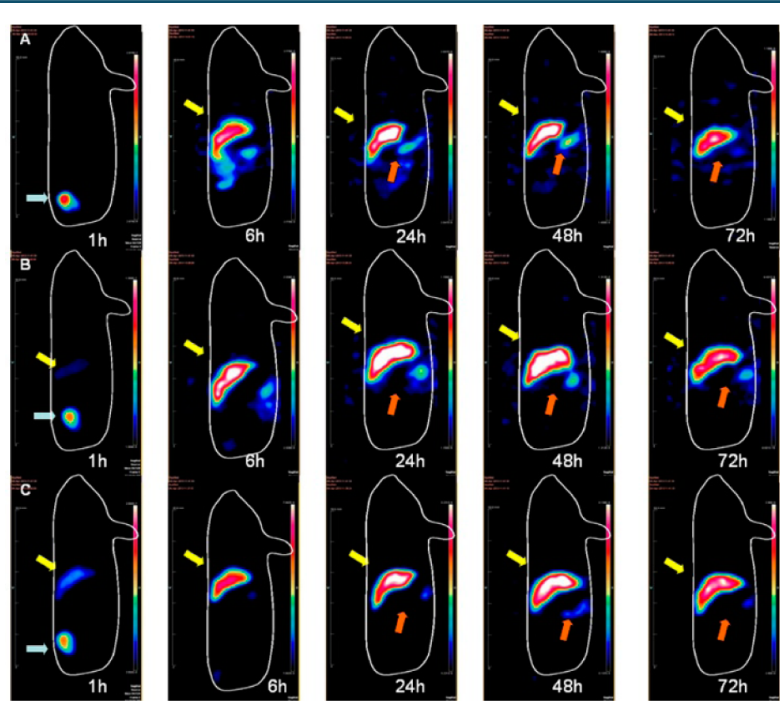

Figure 3. Sagittal SPECT images of three mice acquired at different time points after i.v. injection of (A) $\left[{ }^{111} \mathrm{In}\right]$ DOTAdex, (B) $\left[{ }^{111} \mathrm{In}\right]$ DOTAdexSPION, and (C) [ ${ }^{111}$ In] DOTAdexPEG_SPION. Color intensity scale is denoted as white $>$ red $>$ yellow $>$ green $>$ blue. The blue, yellow, and orange arrows indicate the bladder, liver, and spleen, respectively.

formulations at different time points after administration. SPECT images were in agreement with the results of the ex vivo biodistribution studies. Highest levels of activity were found in the bladder at $1 \mathrm{~h}$ after injection, which can be assigned to residual free ${ }^{111}$ In or smaller ${ }^{111}$ In-labeled nanogels cleared
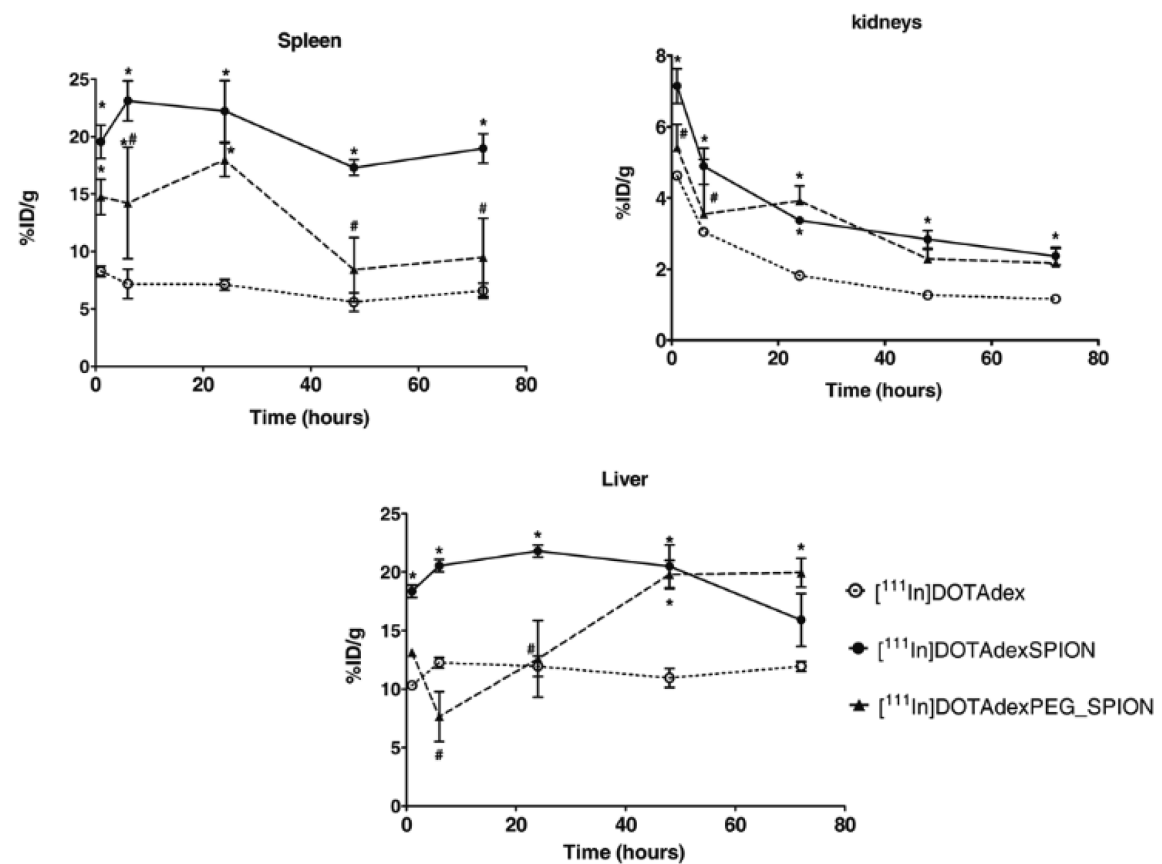

Figure 2. Biodistribution values of [ $\left.{ }^{111} \mathrm{In}\right]$ DOTAdex, $\left[{ }^{111} \mathrm{In}\right]$ DOTAdexSPION, and $\left[{ }^{111} \mathrm{In}\right]$ DOTAdexPEG_SPION in main excretory organs over a period of $72 \mathrm{~h}$. Bars represent mean \pm standard error of the mean of the $\% \mathrm{ID} / \mathrm{g}(n=5) . * p<0.05$ when compared to $\left[{ }^{111} \mathrm{In}\right] \mathrm{DOTAdex},{ }^{\#} p<0.05$ when compared to $\left[{ }^{111} \mathrm{In}\right]$ DOTAdexSPION. 

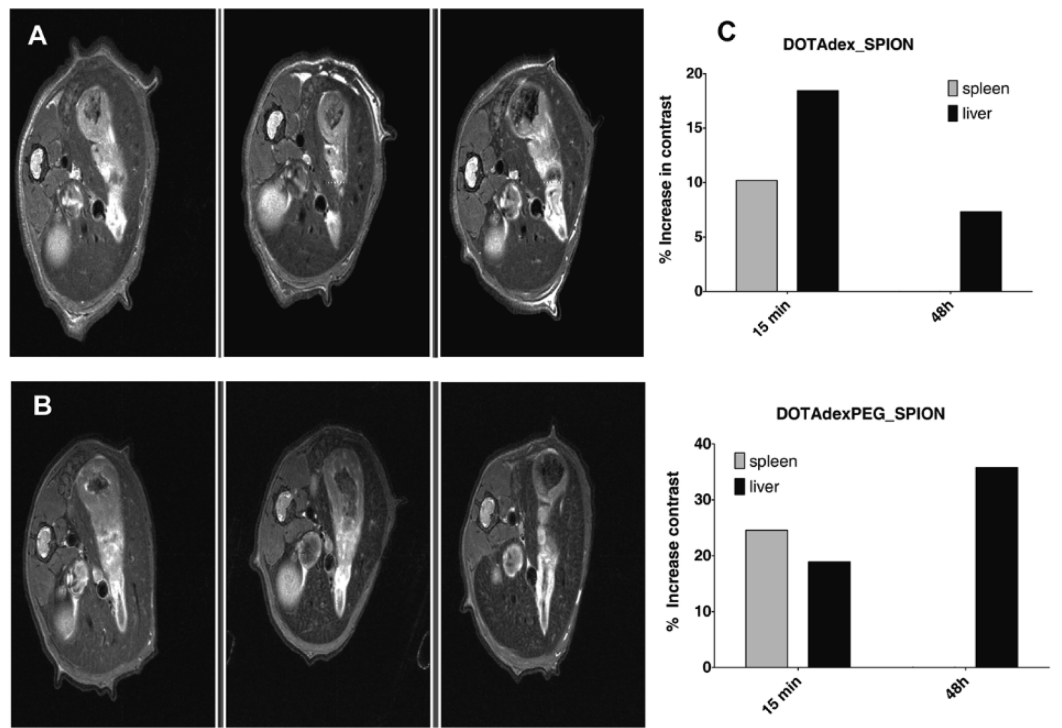

Figure 4. MRI image analysis of mice injected with (A) DOTAdexSPION and (B) DOTAdexPEG_SPION. Images were taken before administration (left), 15 min post-injection (middle) and $48 \mathrm{~h}$ post-injection (right). The percentage of increase in tissue contrast of mice injected with (C) DOTAdexSPION and (D) DOTAdexPEG_SPION, calculated in the T2-weighted images relative to $T=0$, defined as the ratio of gray intensity in the tissue of interest relative to the vertebrae in the same slide. ${ }^{15}$

mainly through the urinary system. At later time points, the activity is mainly located in the liver and spleen (yellow and orange arrows in Figure 3). As expected and in accordance with the biodistribution studies, higher spleen labeling was observed in the mouse injected with unpegylated nanomagnetogels $\left[{ }^{111} \mathrm{In}\right]$ DOTAdexSPION. In addition, the SPECT images showed that at $1 \mathrm{~h}$ after the tracer injection only $20 \% \pm 1 \%$ of the injected dose remains in the animal, indicating that all tracers have a rapid clearance in the first hour mainly through the kidneys/bladder. At the end of the last scans, $72 \mathrm{~h}$ after tracer injection, only $4 \% \pm 0.48 \%$ of the injected dose remained in the body.

We further used two mice to evaluate the in vivo MRI imaging (Figure 4). Each animal was intravenously injected with either DOTAdexSPION or DOTAdexPEG SPION. At 15 min and 48 $\mathrm{h}$ post-injection, both formulations showed an increase in relative contrast in the liver and spleen.

This preliminary imaging study seems to be in agreement with the results of the ex vivo biodistribution study where is observed a lower initial uptake in the liver for pegylated formulations and a continuous uptake. Nonetheless, further animal studies should be pursued in order to further access the potential of these nanomagnetogels as MRI contrast agents.

Nanomagmetogel Stability (in Vivo). The stability of the nanomagnetogel after intravenous administration is essential for its biomedical use. To evaluate the nanomagnetogel stability, the iron concentration (physically loaded through hydrophobic interactions) in the spleen (whole organ) was quantified by ICP, $48 \mathrm{~h}$ post-injection, and correlated with the polymer quantification performed by scintigraphy (\%ID/g).

The ICP measurements (Figure 5) demonstrate a good correlation between the amount of polymer (expressed as \%ID/ g) and the amount of iron (quantified by ICP). It should be noted that this is a correlation between two parameters quantified through different techniques in a biological sample; therefore, we assume a good correlation.

$$
y=28.959 x-1.692, \quad r^{2}=0.75, \quad P=0.0027
$$

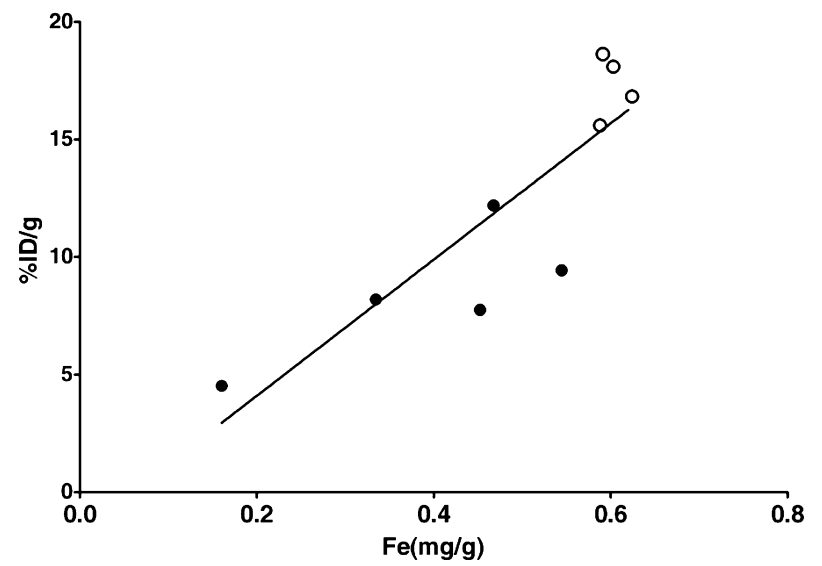

Figure 5. Correlation between the uptake values $(\% \mathrm{ID} / \mathrm{g})$ of $(\mathrm{O})$ $\left[{ }^{111} \mathrm{In}\right]$ DOTAdexSPION or $(\bullet)\left[{ }^{111} \mathrm{In}\right]$ DOTAdexPEG_SPION and the amount of iron $(\mathrm{Fe})$ present in the spleen, determined by ICP at $48 \mathrm{~h}$ post-injection.

\section{DISCUSSION}

Particle size and surface properties (chemical structure, functional groups, and charge) play an important role in the in vivo behavior of nanogels. Variation of these parameters can strongly affect their fate in vivo. Modification of the nanomagnetogel with PEG is expected to modulate its interaction with proteins and cells. The PEG hydrophilic corona may avoid or at least minimize the recognition and uptake of the nanosystem by the organs of the mononuclear phagocytic system, thus increasing its blood circulation time. ${ }^{16,17}$ Grafting of the dextrin backbone with DOTA-monoamide type chelators was used to label nanogels with a radioactive metal ion (e.g., ${ }^{111} \mathrm{In}^{3+}$ ) for biodistribution and imaging studies. The DOTA-monoamide type chelator forms an overall neutral chelate with ${ }^{111} \mathrm{In}^{3+}$. As a result, the labeling procedure does not change the overall (neutral) charge of the original (unlabeled) nanomagnetogel and therefore is not 
expected to substantially affect its biodistribution. ${ }^{6}$ Moreover, the DOTA scaffold forms exceptionally thermodynamically stable and kinetically inert complexes with a range of metal ions $\left(\mathrm{Gd}^{3+}\right.$ for MRI, ${ }^{111} \mathrm{In}^{3+}$ for SPECT, ${ }^{90} \mathrm{Y}^{3+}$ for therapy, ${ }^{68} \mathrm{Ga}^{3+}$ for PET $) .{ }^{18}$ The M(DOTA) complexes are so stable $(\log \mathrm{K} \operatorname{In}(\mathrm{DOTA})=$ 23.9) that their stability does not compromise their in vivo applications. $^{19,20}$

Numerous experimental and clinical studies have shown that, after tumor accumulation, the use of high relaxivity contrast agents results in improved detection and delineation of tumors allowing a more reliable diagnosis. ${ }^{21}$ SPION are generally used as $T_{2}$ (negative) MRI contrast agents. ${ }^{22,23}$ Higher relaxivity contrast agents induce equivalent shortening of the relaxation times $\left(T_{1,2}\right)$ of the water protons of tissues at lower doses, thus allowing reduction of the doses, and so minimizing potential side effects. The nanomagnetogels described in this work, dexSPION and dexPEG_SPION, are promising $T_{2}$ contrast agents owing to their $r_{2}$ values and $r_{2} / r_{1}$ ratio, higher than those displayed by other commercial $\mathrm{Fe}_{2} \mathrm{O}_{3}$ nanoparticulate contrast agents. The magnetic properties were not significantly affected by the introduction of PEG chains on the nanomagnetogel surface. The TEM images demonstrate that nanomagnetogels comprise clusters of magnetic iron oxide nanoparticles that should be coupled to the alkyl chains within hydrophobic domains (Figure S4, Supporting Information).

The obtained blood clearance profiles are clearly different from free $\left[{ }^{111} \mathrm{In}\right]$ or $\left[{ }^{111} \mathrm{In}\right]$ DOTA which are known to clear almost entirely from the bloodstream within $30 \mathrm{~min}$ postinjection. ${ }^{24}$ The smaller unloaded $\left[{ }^{111} \mathrm{In}\right]$ DOTAdex nanogel showed significantly higher blood levels $1 \mathrm{~h}$ after injection, as compared to the larger nanomagnetogels. However, at longer periods no significant differences appear between formulations regarding blood levels. Fitting the blood retention to a monoexponential decay model affords a blood half-life of approximately $4 \mathrm{~h}$, which is much longer than the commercially available SPIONs such as Resovist $(5 \mathrm{~min})^{15}$ and Endorem (6 $\mathrm{min}){ }^{25}$ Nanoparticulate systems displaying hydrophobic surfaces are readily opsonized resulting in efficient uptake by the mononuclear phagocytic system and fast blood clearance. For these systems, PEGylation often results in enhancement of plasma lifetime, due to strong inhibition of the opsonization mechanisms. Sugars and polysacharides have been reported to display anti-adhesive properties similar to PEG. Thus, the addition of PEG chains to the already hydrophilic polysaccharide backbone, as in this work, can only produce a minor effect on the plasma lifetime.

The uptake profiles in the liver, spleen, and kidneys showed lower uptake of unloaded nanogel than nanomagnetogels. Since the unloaded nanogel is substantially smaller $(\sim 30 \mathrm{~nm})$ than the loaded nanomagnetogel $(\sim 110 \mathrm{~nm})$, these results may be due to an effect of particle size on the biodistribution profile. ${ }^{26}$ The uptake of pegylated nanomagnetogels was found to be significantly lower in the spleen at all times, when compared to unpegylated formulations. The SPECT imaging study revealed good agreement with ex vivo results, such as accumulation in the liver and spleen and higher levels of activity in the spleen of mouse injected with unpegylated nanomagnetogels when compared with pegylated formulations. MRI images also revealed improved tissue contrast using pegylated nanomagnetogel.

The stability of the nanomagnetogel, after intravenous administration, is essential for its biomedical application. The nanosystem needs a period of circulation in the bloodstream without release of the iron particles to allow the carrier system to reach the target. To further check whether the nanomagnetogels remain stable during the biodistribution process, the amount of elemental iron in the spleen (whole organ) was also analyzed by ICP. A good correlation between the amount of polymer (expressed as \%ID/g) and the amount of iron (quantified by ICP) was obtained indicating the colocalization of SPIONs with the labeled polymer, i.e., the absence of leakage of iron from the nanogels, after intravenous administration, suggesting high stability of the nanomagnetogels in vivo.

\section{CONCLUSION}

The in vivo study of dextrin nanomagnetogels demonstrated high stability after intravenous administration in a mice model, a remarkable result taking in account the self-assembling organization of the material. The amount of elemental iron in the spleen (ICP analysis) presented a good correlation with the amount of polymer (radioactivity quantification), indicating the absence of leakage of iron from the polymeric matrix. Therefore, the proposed formulation allows a stable and safe iron transport through the bloodstream without release of the iron particles, allowing proper targeting and avoiding toxicity effects. Regarding the biodistribution profile, pegylated nanomagnetogels resulted in a significant reduction of spleen accumulation. The blood halflife obtained was approximately $4 \mathrm{~h}$ for all formulations, which is a much longer circulation time than any commercially available SPION such as Resovist ( $5 \mathrm{~min})$ and Endorem $(6 \mathrm{~min})$. The next step would be the evaluation of tumor accumulation using xenograft models and eventually exploring an active targeting strategy.

\section{EXPERIMENTAL SECTION}

Materials. Dextrin-VA (dexVA) and dextrin-VA-SC 16 $\left(\operatorname{dexC}_{16}\right)$ were synthesized as described before. ${ }^{27}$ DexVA consists of a dextrin backbone $(\mathrm{Glc}(\alpha 1 \rightarrow 6) \mathrm{Glc})$ with grafted acrylate ester groups (VA-vinyl group). DexC 16 is composed by the hydrophilic dextrin backbone with grafted VA groups, which are partially substituted with long alkyl chains $\left(\mathrm{SC}_{16}\right)$. In this work, dexC $\mathrm{C}_{16}$ with 30 vinyl groups $\left(\mathrm{DS}_{\mathrm{VA}} 30 \%\right)$ and 4.5 hexadecanethiol chains ( $\left.\mathrm{DS}_{\mathrm{SC} 16} 4.5 \%\right)$ per 100 dextrin glucopyranoside residues was used. $\mathrm{O}$-[2-(3-Mercaptopropionylamino)ethyl]-Omethylpolyethylene glycol 5000 (PEG-SH), dimethyl sulfoxide (DMSO), and triethylamine (TEA) were purchased from Aldrich. Solvents used were of reagent grade and purified by usual methods. $\left.{ }^{[111} \mathrm{In}\right] \mathrm{Cl}_{3}$ was purchased from Covidien. Instant thin layer chromatography silica gel impregnated glass fiber (ITLC-SG) strips were purchased from Pall Life Science. $\omega$ Thiol functionalized metal chelator was synthesized according to Scheme S1 presented and described in the Supporting Information.

Preparation of DOTAdex and DOTAdexPEG. In the first step, dexVA was reacted with the $\omega$-thiol functionalized metal chelator to afford the metal chelator grafted material. In the second step, hexadecanethiol was added to the former material to afford the DOTAdex material. Finally, a thiol functionalized PEG molecule (O-[2-(3-mercaptopropionylamino)ethyl]- $O^{\prime}$-methylpolyethylene glycol 5000) was added to produce the DOTAdexPEG material. Briefly, dexVA (100 mg, DSVA 30\%, $164 \mu$ mol equivalent VA) was dissolved in DMSO $(3.7 \mathrm{~mL})$. To this solution $\omega$-thiol functionalized metal chelator $(63 \mathrm{mg}, 121$ $\mu \mathrm{mol}, 74 \% \mathrm{~mol}$ to VA groups) and triethylamine (64 $\mu \mathrm{L}, 462$ $\mu \mathrm{mol}, 2.8 \mathrm{~mol}$ equiv to VA groups) were added. The medium was 
stirred for $72 \mathrm{~h}$ at room temperature. The mixture was dialyzed (molecular weight cutoff 1000) for $48 \mathrm{~h}$ against water, with frequent water changes. After freeze-drying, a white candyflosslike material was obtained and stored at room temperature. The number of DOTA groups attached to the polymer backbone was estimated $(0.0735 \mu \mathrm{mol} / \mathrm{mg}$ dry material $)$ by back-titration of excess (uncomplexed) $\mathrm{In}^{3+}$ with EDTA in the presence of the complexometric indicator, xylenol orange, following incubation of the metal derivatized polyssacharide with excess ${\operatorname{~}{ }^{3+}}^{3+}$ In the second step grafting of 1-hexadecanethiol to the metal chelator derivatized material was performed as previously reported. ${ }^{27}$ Briefly, $100 \mathrm{mg}$ of material was dissolved in DMSO $(3.7 \mathrm{~mL})$. To this solution, hexadecanethiol $(30 \mathrm{mg}, 116 \mu \mathrm{mol}, 71 \%$ relatively to initial VA groups) and triethylamine $(21 \mu \mathrm{L}, 152 \mu \mathrm{mol}, 0.9$ mol equivalent to VA groups), were added. The medium was stirred for $48 \mathrm{~h}$, at $50^{\circ} \mathrm{C}$, and then dialyzed for $48 \mathrm{~h}$ against water, with frequent water changes. After freeze-drying, DOTAdex was obtained as a white candyfloss-like material and stored at room temperature. DOTAdexPEG was obtained by performing the Michael addition of thiolated-PEG (PEG-SH) to the functionalized dextrin (DOTAdex), as previously reported. ${ }^{6}$ Briefly, DOTAdex $(30 \mathrm{mg})$ and PEG-SH $(25 \mathrm{mg}, 5 \mu \mathrm{mol})$ were dissolved in DMSO $(0.350 \mathrm{~mL})$ and triethylamine $(2.5 \mu \mathrm{L}, 18$ $\mu \mathrm{mol}$ ) was added. The mixture was stirred for $48 \mathrm{~h}$, at $50^{\circ} \mathrm{C}$, and then dialyzed for $48 \mathrm{~h}$ against water, with frequent water changes. After freeze-drying, DOTAdexPEG was obtained as a white candyfloss-like material and stored at room temperature.

Nanomagnetogel Preparation. The nanogel was obtained by polymer dispersion (lyophilized powder) in distilled water $(2.0 \mathrm{mg} / \mathrm{mL})$, under stirring at $50{ }^{\circ} \mathrm{C}$, until a clear colloidal suspension was obtained. The dispersion was then filtered through a $0.22 \mu \mathrm{m}$ syringe filter. Self-assembly of the polymer generates nanostructures that are stabilized by hydrophobic domains $^{28}$ and enable the solubilization of hydrophobic molecules. ${ }^{29}$ Bare $\gamma-\mathrm{Fe}_{2} \mathrm{O}_{3}$ nanoparticles were prepared as previously published. ${ }^{30}$ Briefly, the first step is to add dimethylamine $\left(\left(\mathrm{CH}_{3}\right)_{2} \mathrm{NH}\right)$ to an aqueous micellar solution of ferrous dodecyl sulfate $\left(\mathrm{Fe}(\mathrm{DS})_{2}\right)$. The final concentrations after mixing of the reactants are $1.3 \times 10^{-2} \mathrm{M}$ and $8.5 \times 10^{-1} \mathrm{M}$ for $\mathrm{Fe}(\mathrm{DS})_{2}$ and $\left(\mathrm{CH}_{3}\right)_{2} \mathrm{NH}$, respectively. The solution is stirred vigorously for $2 \mathrm{~h}$ at $28.5{ }^{\circ} \mathrm{C}$ and the resulting precipitate of uncoated nanocrystals is isolated from the supernatant by centrifugation. In the second step, this precipitate is washed with an acidic solution at $\mathrm{pH} 2\left(\mathrm{HCl} 10^{-1} \mathrm{M}\right) \cdot \gamma-\mathrm{Fe}_{2} \mathrm{O}_{3}$ nanoparticles were loaded into the hydrophobic nanodomains within dextrin nanogel, dispersed in distilled water. The physical entrapment of $\gamma$ - $\mathrm{Fe}_{2} \mathrm{O}_{3}$ into the nanogel was performed following the nanogel preparation procedure, as described above. The required volume of $10 \mathrm{mM} \gamma-\mathrm{Fe}_{2} \mathrm{O}_{3}$ stock solution was added to the nanogel dispersion and the $\mathrm{pH}$ of the dispersion was adjusted to $7.4 \mathrm{using}$ $\mathrm{HCl}$ solution $0.05 \mathrm{M}$. The formulation stirred overnight to allow $\gamma-\mathrm{Fe}_{2} \mathrm{O}_{3}$ incorporation into the nanogel. After that, formulations were centrifuged at $4000 \mathrm{~g}$ for $10 \mathrm{~min}$ (room temperature) to remove free $\gamma-\mathrm{Fe}_{2} \mathrm{O}_{3}$. The produced nanomagnetogel contains $4.0 \mathrm{mM}$ of iron (determined by atomic absorption spectroscopy) and is stable for at least 8 weeks, water dispersion at $4{ }^{\circ} \mathrm{C}$, as previously evaluated by analyzing the size distribution (intensityweighted diameter). ${ }^{11}$

Nanomagnetogel Characterization. Size Distribution and Zeta Potential. The size distribution and zeta potential of nanogels were determined by dynamic light scattering (DLS) with a Malvern Zetasizer, NANO ZS (Malvern Instruments Limited, UK), using a $\mathrm{He}-\mathrm{Ne}$ laser (wavelength of $633 \mathrm{~nm}$ ) and a detector angle of $173^{\circ}$. The nanomagnetogel dispersion $(1 \mathrm{~mL})$ was analyzed at $25{ }^{\circ} \mathrm{C}$. The DLS analysis provides the characterization of a sample through the mean value ( $z$-average) for the size and a width parameter known as polydispersity or polydispersity Index (PdI). The $z$-average diameter is the mean hydrodynamic diameter, determined from the intensity of scattered light, which can be converted to other distributions. In the present work, the $z$-average based on the intensity of scattered light is considered the best approach to the actual size. Nanomagnetogel dispersion was analyzed in a polystyrene cell or in a folded capillary cell, for size distribution or zeta potential measurements, respectively. The zeta potential values were calculated using the Smoluchowski equation. ${ }^{31}$

Relaxometry. Magnetic resonance relaxometry was used to measure the longitudinal $\left(T_{1}\right)$ and transverse $\left(T_{2}\right)$ proton relaxation times for the nanomagnetogel. Measurements were performed using a Bruker Minispec mq20 relaxometer operating at a magnetic field of $0.47 \mathrm{~T}$, corresponding to a Larmor frequency of $20 \mathrm{MHz}$, and at a temperature of $25^{\circ} \mathrm{C}$. $T_{1}$ and $T_{2}$ relaxation times were obtained using the inversion-recovery (IR) and Carr-Purcell-Meiboom-Gill (CPMG) pulse sequences, respectively. The reproducibility of the relaxation time determinations was found to be better than $\pm 1 \%$. The corresponding relaxivity values, $r_{1}$ and $r_{2}$, were calculated through the least-squares curve fitting of $1 / T_{1,2}=R_{1,2}\left(\mathrm{~s}^{-1}\right)$ versus the iron concentration ( $\mathrm{mM} \mathrm{Fe}$ ).

Preparation of Radiolabeled Materials. To a dispersion of DOTAdex, DOTAdex SPION, or DOTAdexPEG SPION in water $(1.0 \mathrm{mg}$ in $500 \mu \mathrm{L}), 100 \mu \mathrm{L}$ of ammonium acetate ( $\mathrm{pH} 5.5)$ and $\left[{ }^{111} \mathrm{InCl}_{3}\right](100 \mathrm{MBq}$ in $100 \mu \mathrm{L})$ were added. The labeling mixture was incubated at $50{ }^{\circ} \mathrm{C}$ for $2 \mathrm{~h}$ in a thermomixer $(400$ $\mathrm{rpm}$ ). The labeling was followed by thin layer chromatography using silica gel strips (ITLC-SG) developed with $0.1 \mathrm{M}$ ammonium acetate $(\mathrm{pH} 5.5) / 0.1 \mathrm{M} \operatorname{EDTA}(1: 1, \mathrm{v} / \mathrm{v})$ as the eluent to determine the percentage of free $\left[{ }^{111} \mathrm{In}\right]\left(\left[{ }^{111} \mathrm{In}\right]\right.$ is used to represent the $\left[{ }^{111} \mathrm{In}^{3+}\right]$ species). TLC strips were analyzed with a TLC VCS-103 radiochromatograph scanner. $\left[{ }^{111}\right.$ In]DOTAdex, $\left[{ }^{111}\right.$ In]DOTAdex_SPION, or [ ${ }^{111}$ In]DOTAdexPEG_SPION remained at the origin, whereas free $\left[{ }^{111} \mathrm{In}\right] \mathrm{Cl}_{3}$ migrates with a Rf of $0.8-0.9$. The labeling efficiency was $45 \%, 80 \%$, and $98 \%$ for $\left[{ }^{111} \mathrm{In}\right]$ DOTAdex, [ $\left.{ }^{111} \mathrm{In}\right]$ DOTAdex_SPION, or $\left[{ }^{111} \mathrm{In}\right]$ DOTAdexPEG_SPION, respectively. Each compound was purified by centrifugation, through a Vivaspin $10 \mathrm{kDa}$, and washed twice with $2 \mathrm{~mL}$ of a PBS ( $\mathrm{pH} 7.4) / E D T A ~(1.25 \mathrm{mg} /$ $\mathrm{mL})$ solution to remove the free $\left[{ }^{111} \mathrm{In}\right]$ as $\left[{ }^{111} \mathrm{In}\right]$-EDTA complex. The products were then dissolved in PBS ( $\mathrm{pH}$ 7.4) to prepare appropriate doses for biodistribution and imaging studies.

Biodistribution Studies. Biodistribution was studied in $\mathrm{BALB} / \mathrm{c}$ mice ( 7 weeks of age, $23-28 \mathrm{~g}$ body weight, Harlan). All animals were housed under standard environmental conditions (free access to food and water and a 12/12 h light/dark cycle), and acclimatized for at least 1 week after arrival before the experiment was started. All animal experiments were approved by the Institutional Animal Care and Use Committee of the University of Groningen and carried out according to the Dutch laws and regulations for animal experiments. The animals were divided in groups of 5 animals and injected with $0.5-2.0 \mathrm{mBq}$ $(0.1-0.15 \mathrm{~mL})$ of ${ }^{111}$ In-labeled nanogel or nanomagnetogel preparation via the penile vein. Mice were sacrificed by cervical dislocation 1, 6, 24, 48, or $72 \mathrm{~h}$ after injection. A blood sample was taken, and tissues of interest were dissected, weighed, and counted in a gamma counter. The uptake of ${ }^{111}$ In-labeled 
nanogels in various organs was measured in counts per minute (CPM), corrected for radioactive decay, for the counting efficiency of the gamma counter, injected dose, and body weight of the animal. Tissue distribution was expressed as percent injected dose per gram of tissue (\%ID/g). The plasma uptake values were used to fit a monoexponential decay function to determine the blood circulation half-life.

SPECT Imaging. Longitudinal imaging was carried out in $\mathrm{BALB} / \mathrm{c}$ mice. The animals were injected in the penile vein with $12-20 \mathrm{MBq}(0.1-0.15 \mathrm{~mL})$ of ${ }^{111}$ In-labeled formulations: $\left[{ }^{111} \mathrm{In}\right]$ DOTAdex, $\left[{ }^{111} \mathrm{In}\right]$ DOTAdexSPION, and $\left[{ }^{111} \mathrm{In}\right]-$ DOTAdexPEG SPION. The animals were anesthetized with $1.5 \%$ isofluorane in medical air and positioned in the U-SPECTII (MILabs) equipped with a mouse multipinhole collimator $(0.6$ $\mathrm{mm}$ diameter). Static whole body tomographic images were acquired for $60 \mathrm{~min}$ immediately after tracer injection and at 5, 23,47 , and $71 \mathrm{~h}$ after tracer injection. Once the scan at $72 \mathrm{~h}$ was completed, the animals were sacrificed by cervical dislocation. A $20 \%$ main photopeak was centered at 171 and $245 \mathrm{keV}$ to reconstruct the ${ }^{111}$ In images on $0.1875 \mathrm{~mm}$ voxels by 2 iterations of 16 subsets (ordered subsets expectation maximization, OSEM). To evaluate the whole-body clearance over time, a region of interest (ROI) was created over the whole body image, at all time points, and compared to the values in the first $10 \mathrm{~min}$ of each scan.

MRI Imaging. A vertical 9.4 T and 89-mm-diameter bore MRI scanner equipped with a $1500 \mathrm{mT} / \mathrm{m}$ gradient set (Bruker Biospin $\mathrm{GmbH}$, Ettlingen, Germany) was used to study the uptake of magnetic particles in the liver and spleen. Mice were anesthetized with $1.5-3.0 \mathrm{vol} \%$ isoflurane in a $2: 1$ mixture of medical air and oxygen. The mice were put on a custom-built cradle and positioned inside a 3 - $\mathrm{cm}$-diameter quadrature volume coil. For cardiac triggering, both cardiac and respiratory motion signals were monitored by a pressure pad placed under the chest of the mouse. After global shimming and RF pulse calibration, scout scans were made to plan 6 short-axis slices through the liver and spleen. The short-axis T2-weighted MR images were obtained with a fast spin echo with fat suppression. Imaging parameters were as follows: repetition time $=2800 \mathrm{~ms}$; echo time $=3.95 \mathrm{~ms}$, effective echo time $=27.65 \mathrm{~ms}$ with a turbo factor $=20$, number of averages $=16$; field of view $=25.3 \times 25.3$; matrix size $=$ $300 \times 300$, in plane resolution $=84 \times 84$ um with a slice thickness $=1 \mathrm{~mm}$; the total acquisition time was $8 \mathrm{~min}$. The mice were then intravenously injected with DOTAdexSPION $(2.84 \mathrm{mg}[\mathrm{Fe}] / \mathrm{kg}$ body weight) or DOTAdexPEG_SPION (3.44 mg $[\mathrm{Fe}] / \mathrm{kg}$ body weight). MRI scans were acquired $15 \mathrm{~min}$ and $48 \mathrm{~h}$ after injection of the formulations. Regions of interest (ROI) were drawn in the selected organs (spleen, liver, and vertebra) and gray scale intensity was measured. The signal-to-noise ratios (SNR) was plotted against time according to the following equations:

$$
\mathrm{SNR}=\text { gray intensity mean value in } \mathrm{ROI} / \mathrm{ROI} \text { mean value }
$$$$
\text { of vertebra in same slice }
$$

$$
\begin{aligned}
& \% \text { increase contrast } \\
& =[1-(\mathrm{SNR} \text { at time } t)] /(\mathrm{SNR} \text { at time zero before } \\
& \quad \text { contrast }) \times 100
\end{aligned}
$$

ICP-MS Analysis. The ICP assays were performed by the Pharmacy laboratories of the University Medical Centre Groningen. Briefly, spleen samples obtained in the biodistribu- tion study at $48 \mathrm{~h}$ post-injection were used for the inductively coupled plasma-mass spectrometry (ICP-MS). The sample matrices were diluted and destroyed in an argon torch of at least $600{ }^{\circ} \mathrm{C}$. The relevant elements remaining in solution were ionized and measured in the mass spectrometer. The measured iron concentrations in the samples were normalized to an ICPMS iron standard.

Statistical Analysis. Differences tissue uptake (\%ID/g) and circulation half-life (hours) between groups were analyzed by two-way analysis of variance (ANOVA) with a Bonferroni posthoc test to correct for multiple comparisons using the Prism v 5 software package (GraphPad, San Diego, CA).

\section{ASSOCIATED CONTENT}

\section{Supporting Information}

Experimental details of the synthesis of the $\omega$-thiol functionalized metal chelator, characterization data: zeta potential, calculation of relaxivities $r_{1}$ and $r_{2}$, magnetic behavior, and transmission electron microscopy. This material is available free of charge via the Internet at http://pubs.acs.org.

\section{AUTHOR INFORMATION}

\section{Corresponding Author}

*E-mail: fmgama@deb.uminho.pt. Tel.: +351 253 604418. Fax: +351253604429.

\section{Present Address}

J. A. Martins is currently on sabbatical leave at the Department of Chemistry, Bath University.

\section{Author Contributions}

J. P. Silva and I. F. Antunes contributed equally to this study. The manuscript was written through contributions of all authors. All authors have given approval to the final version of the manuscript.

\section{Notes}

The authors declare no competing financial interest.

\section{ACKNOWLEDGMENTS}

The authors thank the Project "strong $>$ BioHealth - Biotechnology and Bioengineering approaches to improve health quality", Ref. NORTE-07-0124-FEDER-000027, co-funded by the Programa Operacional Regional do Norte (ON.2 O Novo Norte), QREN, FEDER. The authors thank the Magnisense Corporation for providing a MIAplex Reader and CFGCG the EU COST TD1004 Action "Theragnostics Imaging and Therapy”. The authors thank Professor Cidália Botelho for the iron analysis by Atomic Absorbance Spectroscopy at the Oporto University, Chemical Engineering Department. C. Gonçalves, J. P. Silva, J. A. Martins, and M. F. M. Ferreira acknowledge FCT Portugal, for postdoc grants SFRH/BPD/70524/2010 and SFRH/BPD/64958/2009, sabbatical grant SFRH/BSAB/ $1328 / 2013$ and $\mathrm{PhD}$ grant $\mathrm{SFRH} / \mathrm{BD} / 63994 / 2009$, respectively.

\section{REFERENCES}

(1) Peng, X. H., Qian, X. M., Mao, H., Wang, A. Y., Chen, Z., Nie, S. M., and Shin, D. M. (2008) Targeted magnetic iron oxide nanoparticles for tumor imaging and therapy. Int. J. Nanomed. 3, 311-321.

(2) Yu, W. W., Chang, E., Sayes, C. M., Drezek, R., and Colvin, V. L. (2006) Aqueous dispersion of monodisperse magnetic iron oxide nanocrystals through phase transfer. Nanotechnology 17, 4483-4487.

(3) Tong, S., Hou, S. J., Zheng, Z. L., Zhou, J., and Bao, G. (2010) Coating optimization of superparamagnetic iron oxide nanoparticles for high T-2 relaxivity. Nano Lett. 10, 4607-4613. 
(4) Jung, C. W., and Jacobs, P. (1995) Physical and chemicalproperties of superparamagnetic iron-oxide $\mathrm{mr}$ contrast agents ferumoxides, ferumoxtran, ferumoxsil. Magn. Reson. Imaging 13, 661674.

(5) McCarthy, J. R., and Weissleder, R. (2008) Multifunctional magnetic nanoparticles for targeted imaging and therapy. Adv. Drug Delivery Rev. 60, 1241-1251.

(6) Goncalves, C., Ferreira, M. F. M., Santos, A. C., Prata, M. I. M., Geraldes, C. F. G. C., Martins, J. A., and Gama, F. M. (2010) Studies on the biodistribution of dextrin nanoparticles. Nanotechnology 21, 295103-295111.

(7) Gillis, P., Moiny, F., and Brooks, R. A. (2002) On T-2-shortening by strongly magnetized spheres: A partial refocusing model. Magn. Reson. Med. 47, 257-263.

(8) Carroll, M. R. J., Woodward, R. C., House, M. J., Teoh, W. Y., Amal, R., Hanley, T. L., and St Pierre, T. G. (2010) Experimental validation of proton transverse relaxivity models for superparamagnetic nanoparticle MRI contrast agents. Nanotechnology 21, 35103-35109.

(9) Xie, X. A., and Zhang, C. F. (2011) Controllable assembly of hydrophobic superparamagnetic iron oxide nanoparticle with mPEGPLA copolymer and its effect on MR transverse relaxation rate. J. Nanomater. Article ID 152524, 7 pages.

(10) Berret, J. F., Schonbeck, N., Gazeau, F., El Kharrat, D., Sandre, O., Vacher, A., and Airiau, M. (2006) Controlled clustering of superparamagnetic nanoparticles using block copolymers: Design of new contrast agents for magnetic resonance imaging. J. Am. Chem. Soc. 128, $1755-1761$.

(11) Goncalves, C., Lalatonne, Y., Melro, L., Badino, G., Ferreira, M. F. M., David, L., Geraldes, C. F. G. C., Motte, L., Martins, J. A., and Gama, F. M. (2013) New dextrin nanomagnetogels as contrast agents for magnetic resonance imaging. J. Mater. Chem. B 1, 5853-5864.

(12) Josephson, L., Lewis, J., Jacobs, P., Hahn, P. F., and Stark, D. D. (1988) The effects of iron-oxides on proton relaxivity. Magn. Reson. Imaging 6, 647-653.

(13) Qin, J., Laurent, S., Jo, Y. S., Roch, A., Mikhaylova, M., Bhujwalla, Z. M., Muller, R. N., and Muhammed, M. (2007) A high-performance magnetic resonance imaging T-2 contrast agent. Adv. Mater. 19, 18741878.

(14) de Montferrand, C., Lalatonne, Y., Bonnin, D., Lievre, N., Lecouvey, M., Monod, P., Russier, V., and Motte, L. (2012) Sizedependent nonlinear weak-field magnetic behavior of maghemite nanoparticles. Small 8, 1945-1956.

(15) Khandhar, A. P., Ferguson, R. M., Arami, H., and Krishnan, K. M. (2013) Monodisperse magnetite nanoparticle tracers for in vivo magnetic particle imaging. Biomaterials 34, 3837-3845.

(16) Cole, A. J., David, A. E., Wang, J. X., Galban, C. J., Hill, H. L., and Yang, V. C. (2011) Polyethylene glycol modified, cross-linked starchcoated iron oxide nanoparticles for enhanced magnetic tumor targeting. Biomaterials 32, 2183-2193.

(17) Zhang, Y., Kohler, N., and Zhang, M. Q. (2002) Surface modification of superparamagnetic magnetite nanoparticles and their intracellular uptake. Biomaterials 23, 1553-1561.

(18) Reichert, D. E., Lewis, J. S., and Anderson, C. J. (1999) Metal complexes as diagnostic tools. Coord. Chem. Rev. 184, 3-66.

(19) Clarke, E. T., and Martell, A. E. (1991) Stabilities of the alkalineearth and divalent transition-metal complexes of the tetraazamacrocyclic tetraacetic acid ligands. Inorg. Chim. Acta 190, 27-36.

(20) Heppeler, A., Froidevaux, S., Macke, H. R., Jermann, E., Behe, M., Powell, P., and Hennig, M. (1999) Radiometal-labelled macrocyclic chelator-derivatised somatostatin analogue with superb tumourtargeting properties and potential for receptor-mediated internal radiotherapy. Chem.-Eur. J. 5, 1974-1981.

(21) Laurent, S., Elst, L. V., and Muller, R. N. (2013) Superparamagnetic iron oxide nanoparticles for MRI. The Chemistry of Contrast Agents in Medical Magmetic Resonance Imaging (Merbach, A., Helm, L., and Tóth, E., Eds.) pp 427-447, Chapter 10, John Wiley \& Sons.
(22) Geraldes, C. F. G. C., and Laurent, S. (2009) Classification and basic properties of contrast agents for magnetic resonance imaging. Contrast Media Mol. Imaging 4, 1-23.

(23) Laurent, S., Forge, D., Port, M., Roch, A., Robic, C., Elst, L. V., and Muller, R. N. (2008) Magnetic iron oxide nanoparticles: Synthesis, stabilization, vectorization, physicochemical characterizations, and biological applications. Chem. Rev. 108, 2064-2110.

(24) Al-Jamal, K. T., Nunes, A., Methven, L., Ali-Boucetta, H., Li, S. P., Toma, F. M., Herrero, M. A., Al-Jamal, W. T., ten Eikelder, H. M. M., Foster, J., et al. (2012) Degree of chemical functionalization of carbon nanotubes determines tissue distribution and excretion profile. Angew. Chem., Int. Ed. 51, 6389-6393.

(25) Wang, R. B., Billone, P. S., and Mullett, W. M. (2013) Nanomedicine in action: an overview of cancer nanomedicine on the market and in clinical trials. J. Nanomater. Article ID 629681, 12 pages.

(26) Roohi, F., Lohrke, J., Ide, A., Schutz, G., and Dassler, K. (2012) Studying the effect of particle size and coating type on the blood kinetics of superparamagnetic iron oxide nanoparticles. Int. J. Nanomed. 7, $4447-4458$

(27) Goncalves, C., Martins, J. A., and Gama, F. M. (2007) Selfassembled nanoparticles of dextrin substituted with hexadecanethiol. Biomacromolecules 8, 392-398.

(28) Goncalves, C., and Gama, F. M. (2008) Characterization of the self-assembly process of hydrophobically modified dextrin. Eur. Polym. J. $44,3529-3534$

(29) Goncalves, C., Pereira, P., Schellenberg, P., Countinho, P., and Gama, F. M. (2012) Self-assembled dextrin nanogel as curcumin delivery system. J. Biomater. Nanobiotechnol. 3, 178-184.

(30) Geinguenaud, F., Souissi, I., Fagard, R., Motte, L., and Lalatonne, Y. (2012) Electrostatic assembly of a DNA superparamagnetic nanotool for simultaneous intracellular delivery and in situ monitoring. Nanomedicine: Nanotechnol. Biol. Med. 8, 1106-1115.

(31) Hunter, R. J. (1981) Zeta potential in colloid science. principles and applications. The calculation of zeta potential, pp 59-124, Chapter 3, Academic Press, New York. 